\title{
Cross Saturation Inductance Analysis of a Permanent Magnet Synchronous Motor
}

\author{
L.T. Ergene, Member IEEE, M. Imeryüz and C. Ekin
}

\begin{abstract}
This paper presents the cross saturation effect on a specially designed spoke type permanent magnet synchronous motor (PMSM) for the sensorless vector control. The cross saturation effect becomes very important where the sensorless control algorithm is used. Accurate flux linkage modeling is required to obtain a satisfactory position estimation and eventually minimum induced torque error. The magnetic saturation is the most impacting parameters affecting the position error. Since the $L_{d}$ and $L_{q}$ inductance difference is generally less than $5 \%$ in the spoke type PMSM, the accurate estimation of the cross saturation is critical for the sensorless vector control. In this paper, the designed PMSM has the $L_{d}$ and $L_{q}$ difference in $15 \%$ level even for the overload capacity. So it is even possible to operate the motor in the transient modes with the overload capacity by estimating right cross saturation effect with certain time limits. The mapping of the inductances and efficiency are obtained by using Finite element method and presented in the paper. Some experimental results are also given such as efficiency and power-speed variation at the constant torque.
\end{abstract}

Index Terms-Permanent magnet synchronous motor, finite element method, cross saturation effect, d-q inductances, sensorless vector control.

\section{INTRODUCTION}

$\mathrm{T}$ HE rapid developments in magnetic materials used in the production of electric motors has led to the development of special electric motors such as brushless DC, permanent magnet synchronous motors with the electronic commutation. Reaching high speeds in the electronic components used in motor drive systems and the cost reduction in the manufacturing are also supporting this development. It is very critical to find the most suitable motor and drive system in terms of the design and control algorithm for the application. Permanent magnet synchronous motors (PMSM) can be used widely in the systems from low to medium power because of their high efficiency, high torque/inertia ratio, high reliability and high dynamic performance features. The efficient motor design was the main focus on the early literature [1]. How ever the control algorithms become more important in the recent publication. Generally, ac variable-speed drive of a permanent magnet synchronous motor needs a position sensor for the commutation and also current control.

L. T. ERGENE, is with Department of Electrical Engineering of Istanbul Technical University, Istanbul, Turkey, (e-mail: ergenel@itu.edu.tr).

M. IMERYÜZ, is with Department of Electrical Engineering of Istanbul Technical University, Istanbul, Turkey, (e-mail: imeryuz@itu.edu.tr).

C. EKIN, is with PROMOTE AS, Çorlu, Tekirdag, Turkey, (e-mail: cihad.ekin@promote.com.tr

Manuscript received May 23, 2018; accepted June 10, 2018.

DOI: $\underline{10.17694 / \text { bajece. } 426284}$
Position sensor brings some disadvantages such as increased drive cost, reduced mechanical robustness of the overall system, etc. [2]. Sensorless control solutions have been studied since the beginning of 80s to cope with these drawbacks [3-6]. There are two methodologies in the literature: one is based on the back-EMF and the other is based on the position dependency of the winding. In low speed applications extra high frequency signal should be injected to estimate the rotor flux position. The significant saliency between $\mathrm{Ld}$ and $\mathrm{Lq}$ becomes critical. Interior PM synchronous motors are naturally suitable for the sensorless control because of their saliency. Rahideh et.al. succeeded the high performance direct torque control of PMSM by using fuzzy logic and genetic algorithms in 2007 [7]. Novak et al. used the field oriented control with the flux weakening in 2008 [8]. PMSM with sensorless control requires to take into account the cross saturation carefully. The cross saturation was studied by different researchers. Fuchs et al. pointed the constraints of the model d, q in the case of turbo alternators in 1973 [9]. The similar study was performed on the salient pole synchronous motor and the limitation of classical linear uncoupled model compared to experimental results was shown [10]. Especially the experimental validation of the saturation and cross coupling are studied in some literature [11-14]. This paper presents the analysis of a spoke type PMSM motor with its cross saturation inductances and performance calculations. It is also shown that the motor can be operated with the accurate positioning at under and overload conditions by using the sensorless control without any problem.

\section{CROSS SATURATION OF PMSM}

PMSM motor control systems generally have two-axis model, direct-axis (d-axis) and quadrature-axis (q- axis). Moreover these two-axis inductances, $\mathrm{L}_{\mathrm{d}}$ and $\mathrm{L}_{\mathrm{q}}$ directly affects the performance of the motor, such as output torque. Therefore, the analysis of these inductances is very critical for the dynamic characteristics of the motor. These d- and q-axes inductances are not constant. They are changing under different operating conditions non-linearly because of the varying current phase and magnitude and changing reluctance due to the saturation of the magnetic material [14]. This issue becomes more important especially for the dynamics model of the highly saturated PMSMs [12]-[14]. The cross saturation is taken in to account in the flux models where the models are linear or non-linear. The nonlinear flux linkage equations for a saturated interior type PMSM are given as 
follows

$$
\begin{aligned}
& \lambda_{d}\left(i_{d}, i_{q}\right)=\lambda_{d, P M}+L_{d}\left(i_{d}, i_{q}\right) i_{d}+L_{d q}\left(i_{d}, i_{q}\right) i_{q} \\
& \lambda_{q}\left(i_{d}, i_{q}\right)=\lambda_{q, P M}+L_{q}\left(i_{d}, i_{q}\right) i_{q}+L_{q d}\left(i_{d}, i_{q}\right) i_{d}
\end{aligned}
$$

where $\lambda_{\mathrm{d}}$ and $\lambda_{\mathrm{q}}$ are the total flux linkages in $\mathrm{d}$ and $\mathrm{q}$ axes respecitvely. $\lambda_{\mathrm{d}}, \mathrm{PM}$ and $\lambda_{\mathrm{q}, \mathrm{PM}}$ are the permanent magnet flux linkages in $\mathrm{d}$ and $\mathrm{q}$ axes. The electromagnetic torque equations in synchronous machines is defined as in $\mathrm{Eq}(2)$

$$
T=\frac{3}{2} p\left(\lambda_{d} i_{q}-\lambda_{q} i_{d}\right)
$$

After substituting the non-linear flux linkage equqtions into $\operatorname{Eq}(1)$, the torque equation becomes:

$$
\begin{gathered}
T=\frac{3}{2} p\left(\lambda_{d, P M} i_{q}-\lambda_{q, P M} i_{d}+\right. \\
\left.\left(L_{d}-L_{q}\right) i_{d} i_{q}+L_{d q} i_{q}^{2}-L_{q d} i_{d}^{2}\right)
\end{gathered}
$$

There are five terms in Eq.3. First and second terms represent the permanent magnet components. Third term is the reluctance torque term. Fourt and fifth terms are the cross saturation terms. The stator voltages of the PMSM can be given in dq-reference frame as follows:

$$
\begin{aligned}
& V_{d}=R i_{d}+\frac{d \lambda_{d}}{d t}-\omega \lambda_{q} \\
& V_{q}=R i_{q}+\frac{d \lambda_{q}}{d t}+\omega \lambda_{d}
\end{aligned}
$$

Steady state voltage equations at $\omega$ speed, E back electromotive force (EMF) with the assumption of negligibly small $\lambda_{\mathrm{q}, \mathrm{PM}}$ are given in $\mathrm{Eq}(5)$

$$
\begin{aligned}
& V_{d}=R i_{d}-\omega L_{q} i_{q}-\omega L_{q d} i_{d} \\
& V_{q}=R i_{q}+\omega L_{d} i_{d}+\omega L_{d q} i_{q}+E
\end{aligned}
$$

The cross saturation terms can be approximated by using numerical equations as follows

$$
\begin{aligned}
& L_{d q}\left(i_{d}, i_{q}\right)=\left.\frac{\Delta \lambda_{d}}{\Delta i_{q}}\right|_{i_{d}=\text { constant }} \\
& L_{q d}\left(i_{d}, i_{q}\right)=\left.\frac{\Delta \lambda_{q}}{\Delta i_{d}}\right|_{i_{q}=\text { constant }}
\end{aligned}
$$

\section{MODELLING OF PMSM}

\section{A. Specifications of the PMSM}

The test PMSM motor is a special designed and optimized motor which has an efficiency class IE5. The motor has 1.1 kilowatts, 10 Poles, 12 stators slots, ferrite permanent magnets, $3.5 \mathrm{Nm}, 3000 \mathrm{~min}^{-1}$ rated values $\left(500-4000 \mathrm{~min}^{-1}\right.$ without flux weakening and $6000 \mathrm{~min}^{-1}$ with the flux weakening). The needle winding is used for the stator. The motor layout is given in Fig.1. in two and three dimensions.
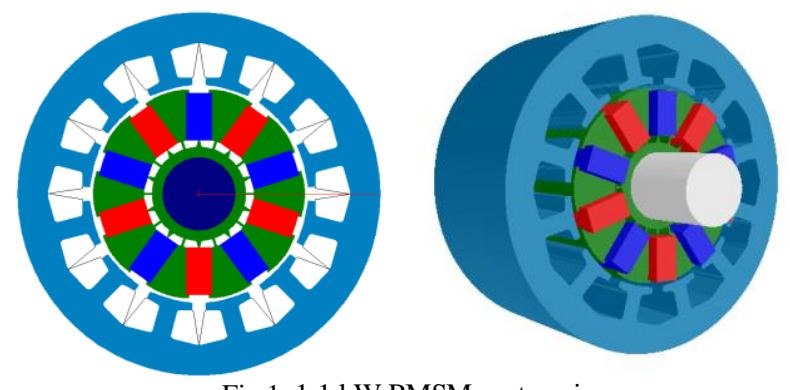

Fig.1. 1.1 kW PMSM motor view.

\section{B. Numerical Modeling of PMSM}

A commercial software (EMAG FEM) which based on Finite Element Method is used for the numerical simulations. The motor half geometry with the equi flux lines are given in Fig.2.

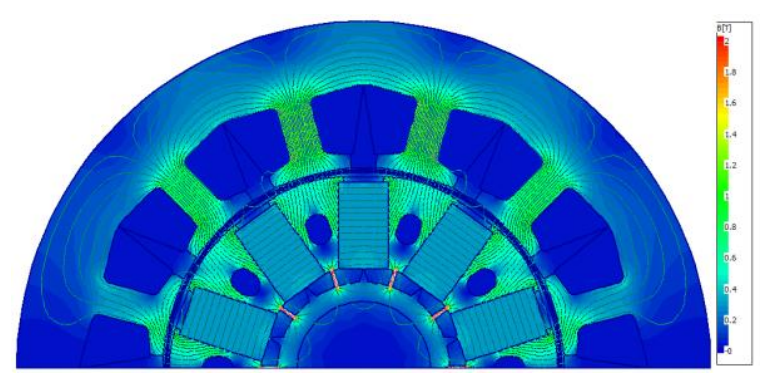

Fig.2. PMSM FEM Model (half of the motor).

The motor is simulated at very low speed to see the reluctance effect as known as the cogging torque. The cogging torque is shown for the half of the motor in Fig.3.

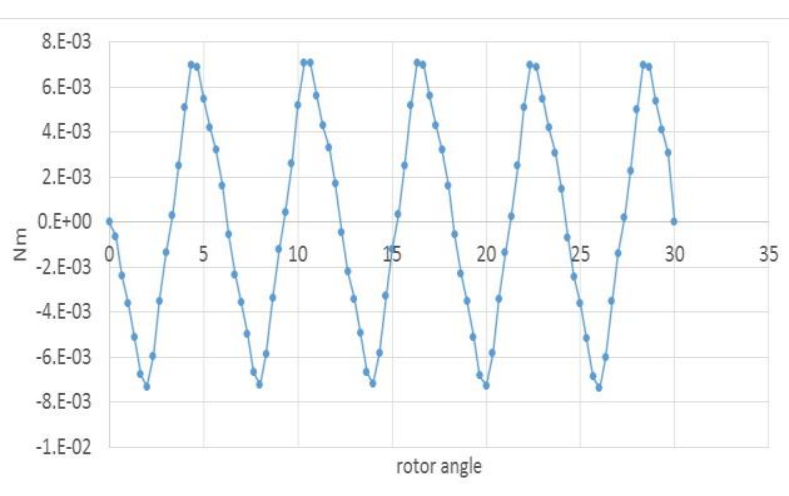

Fig.3. Cogging torque of the PMSM 
The peak to peak value of the cogging torque is $14 \mathrm{mNm}$. Saliency of the motor is about 1.2 for this sensorless vector control algorithm. The motor has the cogging torque less than $1 \%$ of the rated torque. The simulated output torque profile is given in Fig. 4. Torque ripple is less than $10 \%$ of the rated torque.

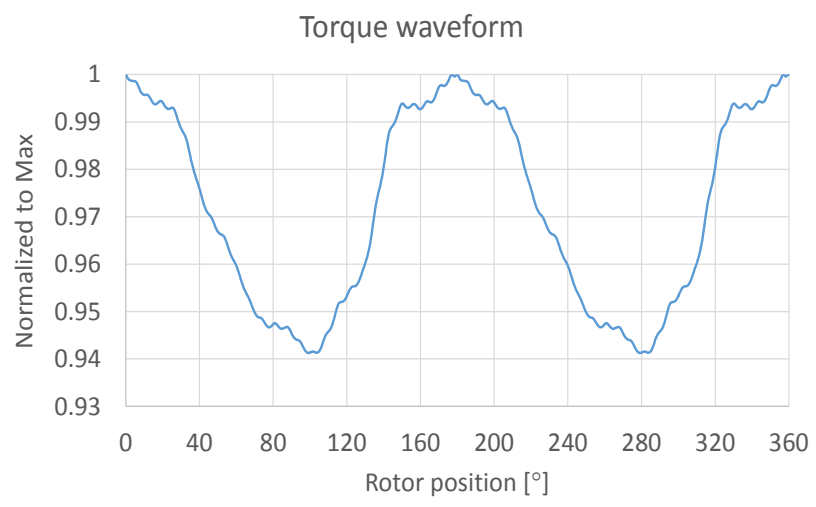

Fig.4. Output torque of the PMSM

The first model would be the no-load operation to calculation of d-axis flux linkage. Later different loading conditions will be applied to obtain $\mathrm{d}$ and $\mathrm{q}$ axes flux linkages. The flux density distributions for the different loadings are given in Fig. 5 .

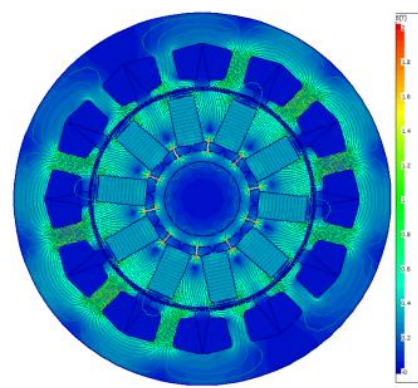

(a)

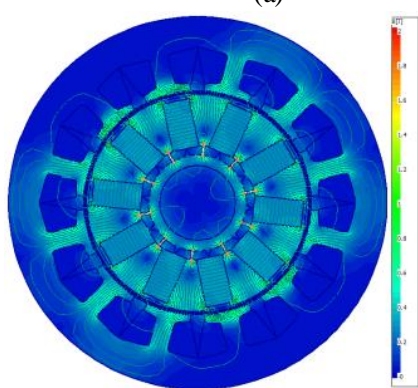

(c)

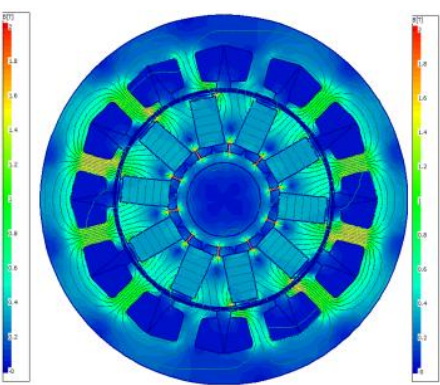

(b)
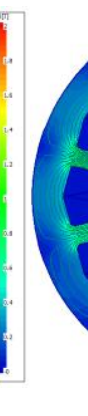

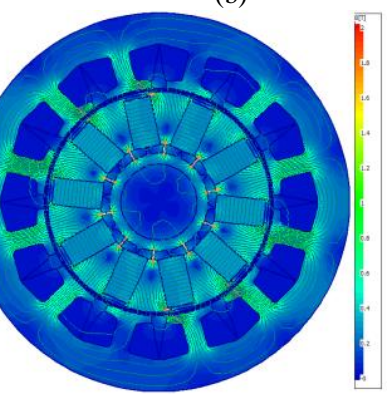

(d)
Fig.5. The flux density distribution (a) No-load at $3000 \mathrm{~min}^{-1} \quad$ (b) q-axis align, $\mathrm{Iq}=2.5 \mathrm{~A}, \mathrm{Id}=0 \mathrm{~A}, 3000 \mathrm{~min}^{-1} \quad$ (c) d-axis align, $\mathrm{Iq}=0 \mathrm{~A}, \mathrm{Id}=2.5 \mathrm{~A}$, $3000 \mathrm{~min}^{-1}(\mathrm{~d}) \mathrm{d}$-axis align, $\mathrm{Iq}=1.8 \mathrm{~A}, \mathrm{Id}=1.8 \mathrm{~A}, 6000 \mathrm{~min}^{-1}$

Fig.6a gives the $d$-axis inductance $\left(L_{d}\right)$ variation due to the $\mathrm{I}_{\mathrm{d}} / \mathrm{I}_{\mathrm{N}}$ and $\mathrm{I}_{\mathrm{q}} / \mathrm{I}_{\mathrm{N}}$ while Fig.6b shows the d-axis flux linkage variation respect to the $I_{d} / I_{N}$ and $I_{q} / I_{N}$ for peak $I_{N}=3.5$ A. The differential inductance method is used to define the inductance values especially in the saturation region. Fig. $7 \mathrm{a}$ and $7 \mathrm{~b}$ present the similar variations for the $\mathrm{q}$-axis inductance and flux linkage respectively for peak $\mathrm{I}_{\mathrm{N}}=3.5 \mathrm{~A}$. Fig.8 a shows $\mathrm{L}_{\mathrm{dq}}$ cross saturation inductance which is calculated by using Equation 5 . $\mathrm{L}_{\mathrm{dq}}$ is calculated by taking the differential $\mathrm{d}$ axis flux change $\left(\lambda_{d}\right)$ respect to $q$ axis current $\left(I_{q}\right)$ while keeping the d-axis current $\left(\mathrm{I}_{\mathrm{d}}\right)$ constant.

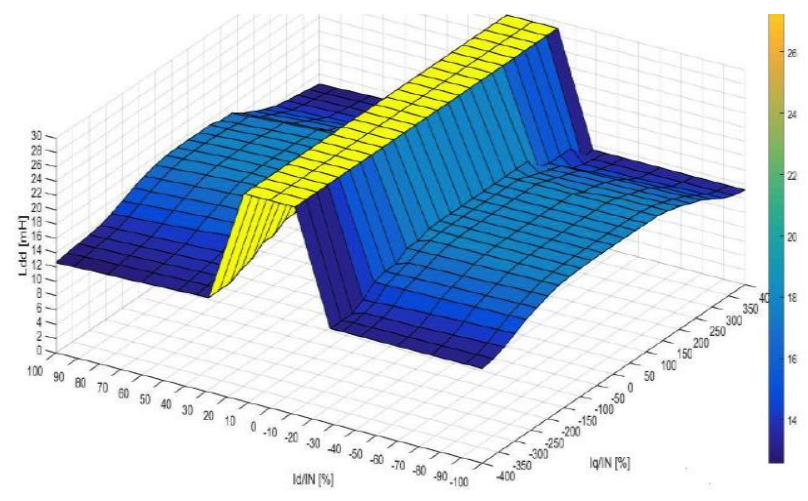

(a)

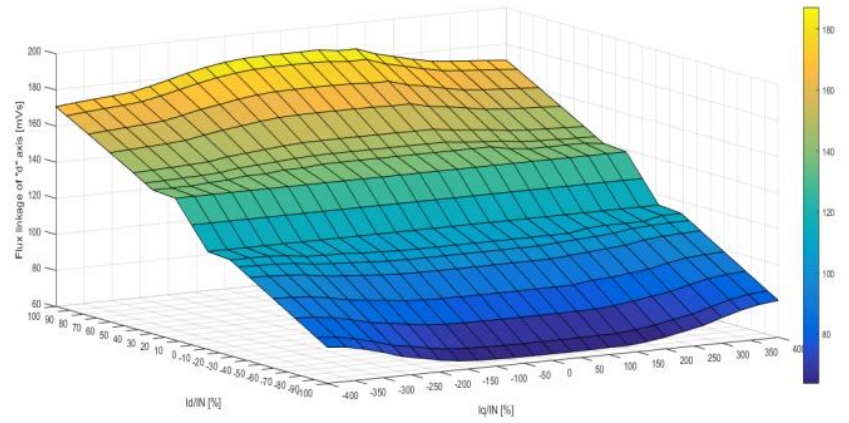

(b)

Fig.6.(a) Ld "d" axis inductance vs Id and Iq currents (b) Flux linkage of "d"axis vs Id and Iq currents

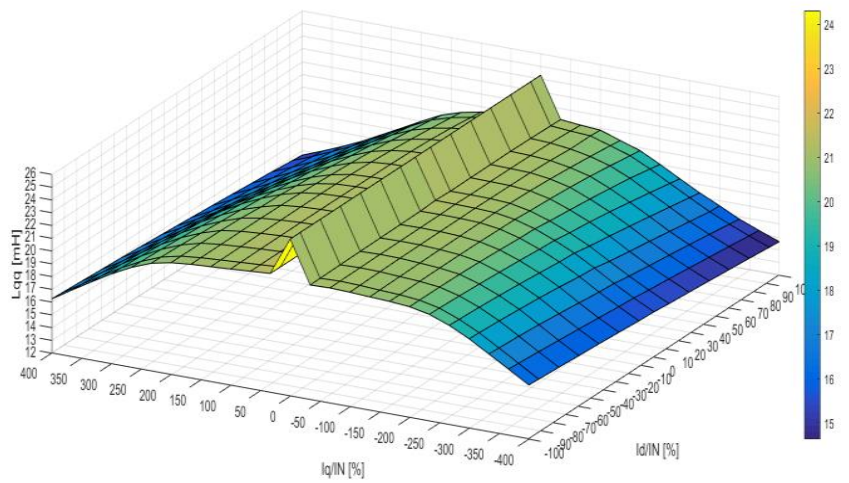

(a)

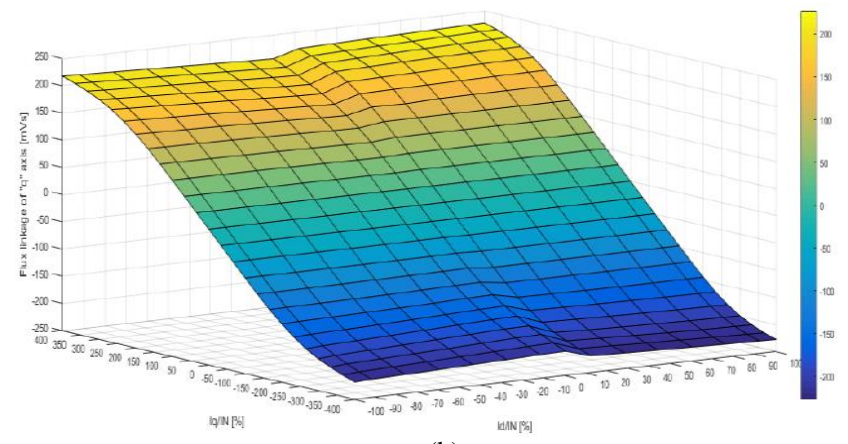

(b)

Fig.7.(a) Lq "q" axis inductance vs Id and Iq currents (b) Flux linkage of "q"axis vs Id and Iq currents 
Similarly, Lqd cross saturation inductance is also calculated by using Eq.6 and drawn as given in Fig. 8 b. $\mathrm{L}_{\mathrm{qd}}$ is calculated by taking the differential $q$ axis flux change $\left(\lambda_{q}\right)$ respect to $d$ axis current $\left(\mathrm{I}_{\mathrm{d}}\right)$ while keeping the $\mathrm{q}$-axis current $\left(\mathrm{I}_{\mathrm{q}}\right)$ constant.

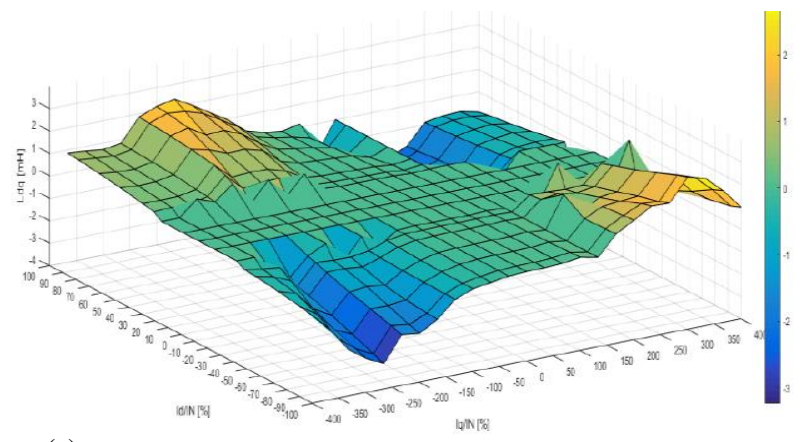

(a)

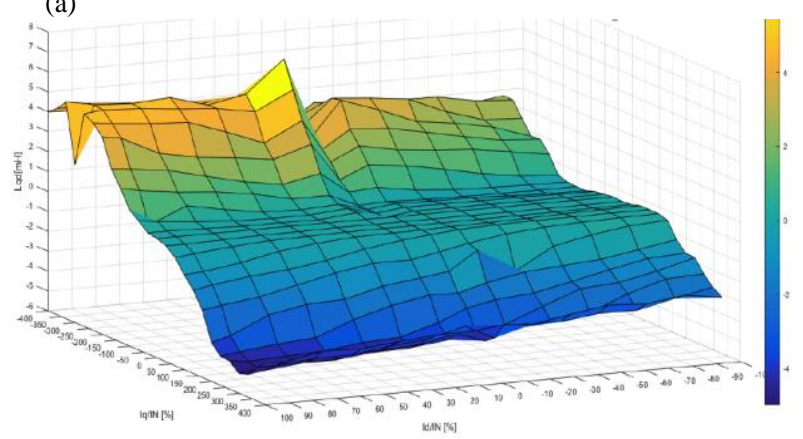

(b)

Fig.8.(a) Ldq cross saturation inductance (b) Lqd cross saturation inductance

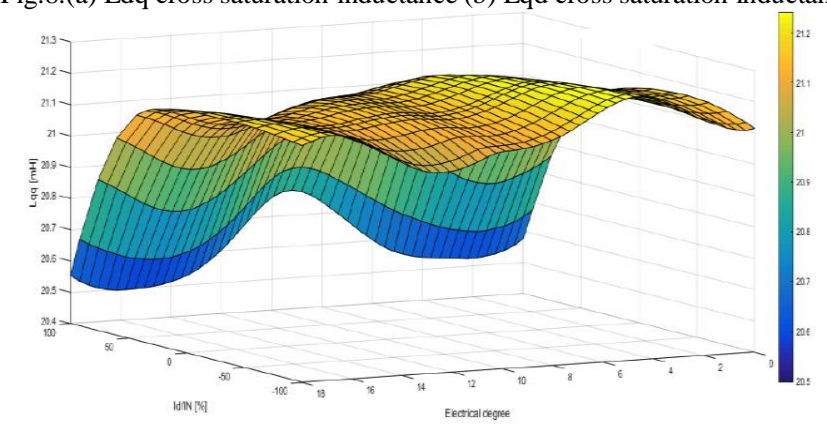

(a)

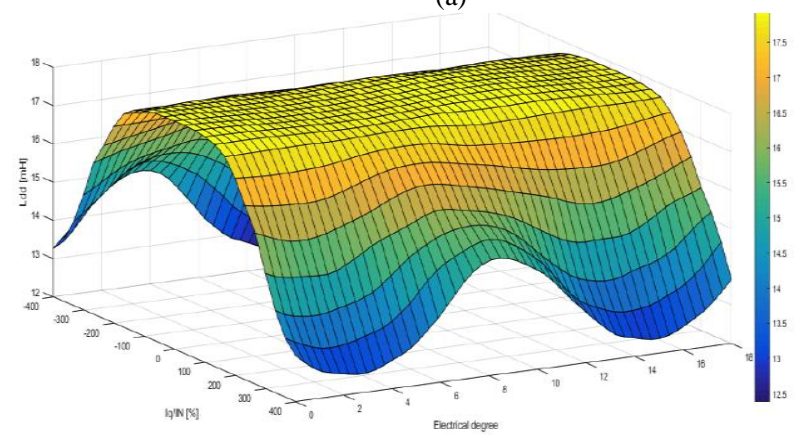

(b)

Fig.9.(a) Lq "q" axis inductance vs Id current and rotor position (Iq=IN, peak=3.5 A) (b) Ld "d" axis inductance vs Iq current and rotor position $(\mathrm{Id}=\mathrm{IN}$, peak $=3.5 \mathrm{~A})$

The efficiency maps of the motor for the power vs. speed and torque vs. speed are given in Fig.10 and Fig.11. Some results can be derived from these inductance and flux linkage profiles: $I_{d}$ current has low effect on "q" axis inductance. $I_{q}$ current has high effect on "d" axis inductance for high current. The motor performs over $90 \%$ efficiency in the $1500-4000 \mathrm{~min}^{-1}$ speed range. The back EMF results of FEM and test are given in Fig. 13 to verify the modeling consistency. The relative erros is less than $1 \%$. Total harmonic distortion is also calculated as less than $1 \%$. For rated performance $\mathrm{I}_{\mathrm{d}}=0$ and doesn't affect "q" axis flux. For rated performance $\mathrm{I}_{\mathrm{d}} \neq 0$ and also doesn't affect "q" axis flux. It doesn't have effect on "d" axis flux, up to rated $\mathrm{I}_{\mathrm{q}}$. For start-up with high torque, high $\mathrm{I}_{\mathrm{q}}$ current affects the control. Saturation effect on $\mathrm{L}_{\mathrm{qq}}$ is $12 \%$ up to the rated current. Saturation effect on $\mathrm{L}_{\mathrm{qq}}$ is $33 \%$ up to four times of the rated current. Saturated saliency is about $\mathrm{L}_{\mathrm{d}} / \mathrm{L}_{\mathrm{q}}=1.17$ up to rated current. Saturated saliency is about $\mathrm{L}_{\mathrm{d}} / \mathrm{L}_{\mathrm{q}}=1.20$ up to the four times of the rated current.

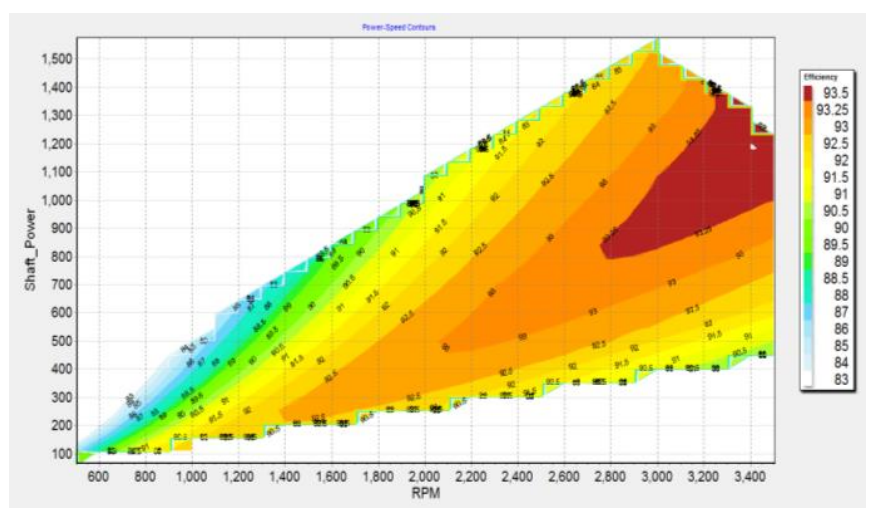

Fig. 10. Efficiency map of the PMSM (power vs. speed)

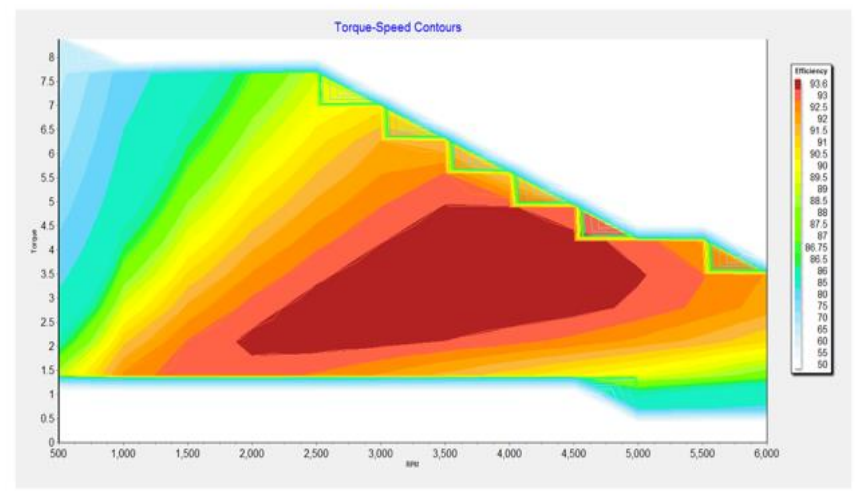

Fig. 11. Efficiency map of the PMSM (torque vs. speed)

\section{EXPERIMENTAL SETUP OF PMSM}

The prototyped PMSM motor and its test setup are given in respectively Fig. 12 and Fig.13. YASKAWA brand driver are used for the vector control. The driver is a commercial type which can be used to drive any type of the motor such as inductance, synchronous reluctance, etc. MAGTROL type hysteresis brake dynamometer is used to load the motor.
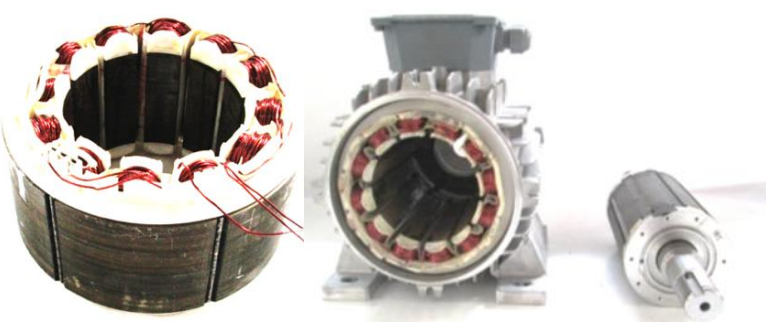

Fig.12. Manufactured PMSM 


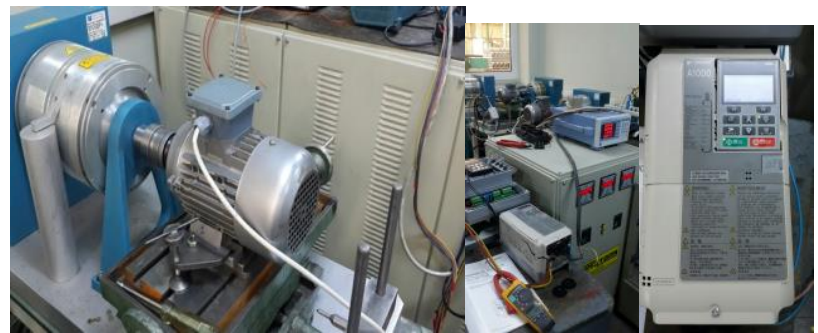

Fig.13. PMSM Experimental Setup

The Back-EMF variation of the motor for the test and simulation results is given in Fig.13.

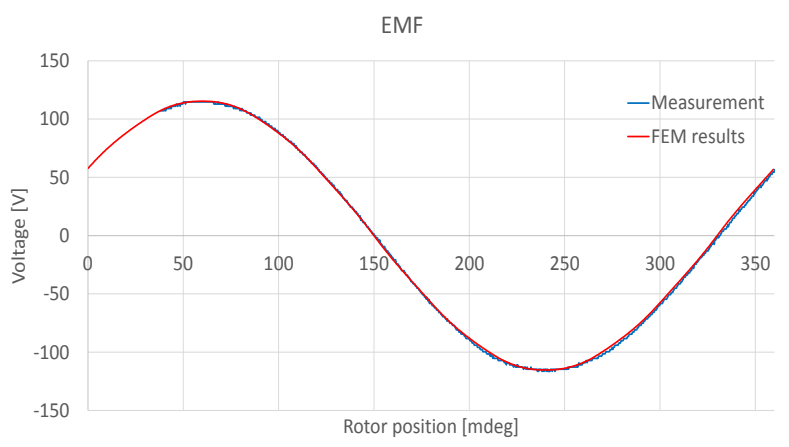

Fig.14. Back-EMF of the PMSM

The output power variation with the speed at constant torque from the test results is presented in Fig. 14. The variation is linear as expected. There is no field weakening in that region. The efficiency with speed from the test results is shown in Fig.16.

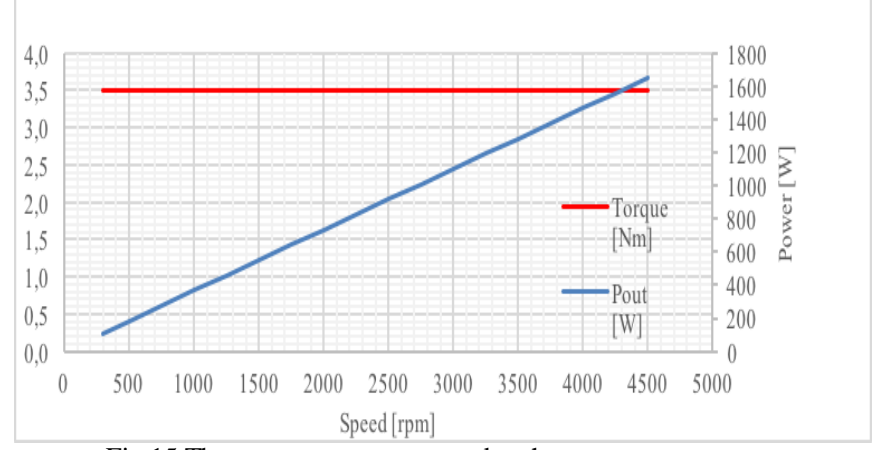

Fig.15.The output power vs. speed at the constant torque

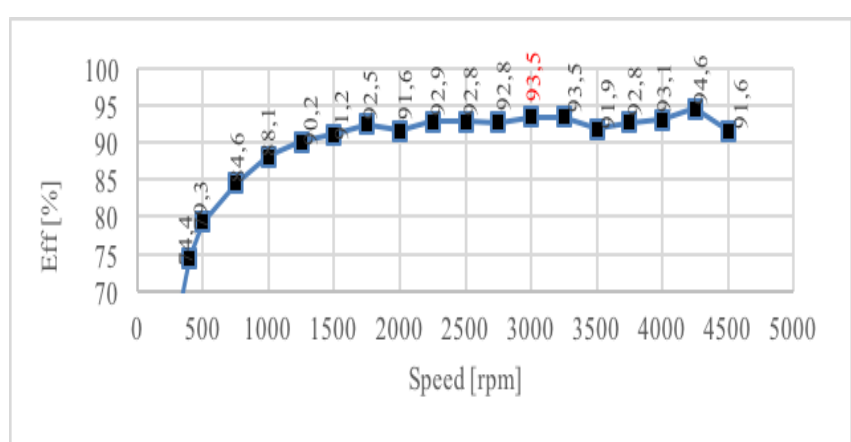

Fig.16. Efficiency vs. speed for the PMSM
Maximum current limit is chosen according to the demagnetization and winding heating. Steady state thermal analysis is used for continuous running region.

\section{CONCLUSIONS}

The paper presents the analysis of a special designed spoke type PMSM motor with the sensorless control for the industrial applications. Saturation of inductances is so important for the sensorless vector control, especially for low speed high torque region. The dynamic and not accurate response in positioning of the Spoke type PMSM with sensorless control because of its low saliency ratio becomes a critical drawback. The result of the motor for a full-speed range is given in Fig. 17.

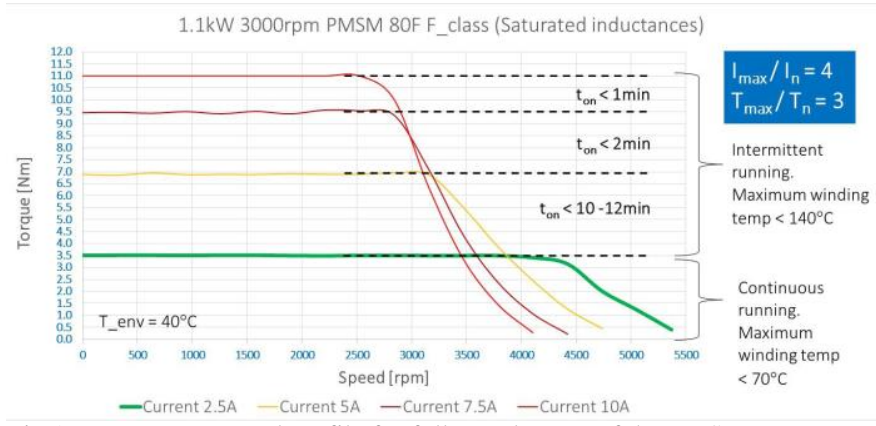

Fig.17. Torque vs. speed profile for full speed-range of the PMSM

The motor overcomes this drawback even in overloading conditions. Three times of the rated torque and four times of the rated current are achieved with control strategy including compensation of the cross-saturation effect.

\section{REFERENCES}

[1] K. Kurihara, M.A. Rahman, "High-Efficiency Line-Start Interior Permanent-Magnet Synchronous Motors", IEEE Transactions on Industrial Applications, Vol.40, No.3, 2004, pp.789-796.

[2] Y. Kano and N. MatsuiSensorless Control of Interior Permanent Magnet Synchronous Motor: An Overview and Design Study, 2017 IEEE Workshop on Electrical Machines Design, Control and Diagnosis (WEMDCD), 2017.

[3] P. Ferraris, A. Vagati, and F. Villata, "PM brushless motor drives: Aselfcommutating system without rotor-position sensors," in Proc. 9thAnnu. Symp. Incremental Motion Contr. Syst., Devices, June 1980, pp.305312.

[4] J.Davoine, R.Perrer, and H. Le-Huy, "Operation of a SelfControlledSynchronous Motor Without a Shaft Position Sensor," IEEE Trans.Ind.Appl., vol. IA-19, pp. 217-222, Mar. 1983.

[5] K. Iizuka, H. Uzuhashi, M. Kano, T. Endo, and K. Mohri, "Microcomputer control for sensorless brushless motor," IEEE Trans. Ind. Appl.,vol. 21, no. 4, pp. 595-601, May/Jun. 1985.

[6] A. Athavale, H. Flieh, B.S. Gagas, T.S. Slininger, R.D. Lorenz, "Machine design for self-sensing", 2016 IEEE Symposium on Sensorless Control for Electrical Drives (SLED), 2016.

[7] A. Rahideh, A. Rahideh, M. Karimi, A. Shakeri, M. Azadi, "High Performance Direct Torque Control of a PMSM Using Fuzzy Logic And Genetic Algorithm", IEEE International Conference on Electric Machines \& Drives, Antalya, TURKEY, 2007.

[8] J. Simanek, J. Novak, O. Cerny, R. Dolecek, "FOC and Flux Weakening for Traction Drive with Permanent Magnet Synchronous Motor", Proceedings of IEEE International Symposium on Industrial Electronics, Cambridge, UK, 2008.

[9] E. Fuchs, E. Erdelyi "Nonlinear Theory of Turboalternators, Part II. Load Dependent Synchronous Reactances", IEEE Transactions on Power Apparratus and Systems, Vol. 92, No.2, 1973, pp.592-599. 
[10] M. Kamoun, M. Poloujadoff, "Experimental Study of The Effect of Saturation on The Steady State Operation of a Salient Pole Microalternator", Electrical Machines and Power Systems, Vol.10, 1985, pp.325-334.

[11] K. Saleh, M. Sumner, "Sensorless Speed Control of Five-Phase PMSM Drives with Low Current Distortion", Electrical Engineering, 2017, pp.1-18.

[12] B. Stumberger, G. Stumberger, D. Dolinar, A. Hamler, M. Trlep, "Evaluation of Saturation and Cross-Magnetization Effects in Interior Permanent-Magnet Synchronous Motor", IEEE Transactions on Industrial Applications, Vol.39, No.5, 2003, pp.1264-1271.

[13] A.M. El-Serafi, A.S. Abdallah, M.K. El-Sherbiny, E. Badawy, "Experimental Study of The Saturation and the Cross-Magnetizing Phenomenon in Saturated Synchronous Machines", IEEE Transactions on Energy Conversion, Vol.2, No.4, 1988, pp.815-823.

[14] E. Levi, V.A. Levi, "Impact of Dynamic Cross-Saturation on Accuracy of Saturated Synchronous Machine Models", IEEE Transactions on Energy Conversion, Vol.15, No.2, 2000, pp.224-230.

[15] E. Oksuztepe, Z.Omac, H. Kurum, "Sensorless Vector Control Of PMSM With Non-Sinusoidal Flux Using Observer Based On FEM", Electrical Engineering, Vol.96, No.3, September 2014, pp. 227-238.

\section{BIOGRAPHIES}

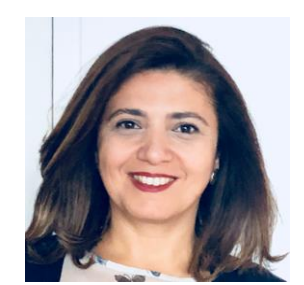

Lale T. Ergene received her BS and M.Sc. degrees in Electrical Engineering at Istanbul Technical University (ITU) in 1992 and 1995 respectively and Ph.D. degree in Electrical Power Engineering at Rensselaer Polytechnic Institute (RPI), NY, USA in 2003. She worked as consultant engineer at MAGSOFT Corporation during 1999-2004. She was also an adjunct assistant professor at RPI in 2004. From 2004 to 2009, she was an assistant professor at the Informatics Institute, ITU. She joined to the faculty of Electrical Engineering, Istanbul Technical University in 2009. She is currently an associate professor at the same department. Her current research interests include design, analysis, control of electrical machines and alternative energy technologies.

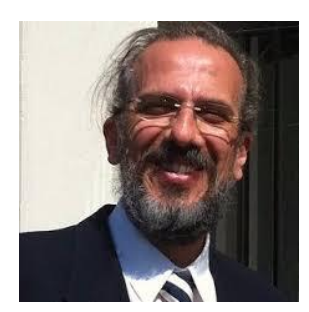

Murat İmeryüz was born in Ankara in 1967. He graduated from Suadiye High School and started undergraduate education in 1984 at the Istanbul Technical University, Faculty of Electric \& Electronics, Department of Electrical Engineering. He completed his undergraduate education in 1989 and M.Sc. degree in 1994 in Electrical Engineering major. He is working at the same department since 1990. His current research interests are fault diagnosis in asynchronous machines, electrical drive systems, analytical calculation of electrical machines and solar energy systems.

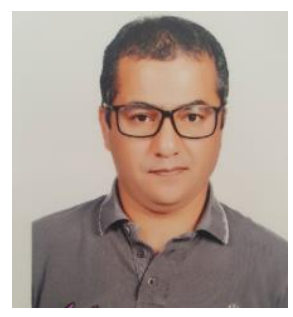

Cihad Ekin received his BS degree in Electrical Engineering at Istanbul Technical University (ITU) in 1997. He worked as design team leader at ARCELİK AS between 1997-2013. He is currently the Vice Director of PROMOTE AS. He has several patents on electrical motors. His research interests include design, analysis, control of PM motors. 